\title{
Rigoulet-Roze D., Géopolitique de l'Arabie saoudite
}

Paris, Armand Colin, coll. Perspectives géopolitiques, 2005

\section{Julien Vandeburie}

\section{(2) OpenEdition}

\section{Journals}

Édition électronique

URL : http://journals.openedition.org/belgeo/12243

DOI : $10.4000 /$ belgeo. 12243

ISSN : 2294-9135

Éditeur :

National Committee of Geography of Belgium, Société Royale Belge de Géographie

\section{Édition imprimée}

Date de publication : 31 décembre 2005

Pagination : 528

ISSN : 1377-2368

\section{Référence électronique}

Julien Vandeburie, «Rigoulet-Roze D., Géopolitique de l'Arabie saoudite», Belgeo [En ligne], 4 | 2005, mis en ligne le 29 octobre 2013, consulté le 22 septembre 2020. URL : http://journals.openedition.org/ belgeo/12243; DOI : https://doi.org/10.4000/belgeo.12243

Ce document a été généré automatiquement le 22 septembre 2020.

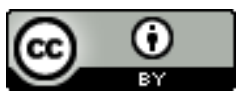

Belgeo est mis à disposition selon les termes de la licence Creative Commons Attribution 4.0 International. 


\title{
Rigoulet-Roze D., Géopolitique de l'Arabie saoudite
}

Paris, Armand Colin, coll. Perspectives géopolitiques, 2005

\author{
Julien Vandeburie
}

\section{RÉFÉRENCE}

Rigoulet-Roze D., Géopolitique de l'Arabie saoudite, Paris, Armand Colin, coll. Perspectives géopolitiques

1 Peu d'ouvrages de géographie s'intéressent à l'Arabie saoudite et si on a vu fleurir après le 11 septembre 2001 un grand nombre d'analyses "géopolitiques », ces dernières n'en avaient souvent que l'étiquette. Le présent ouvrage, publié dans une collection dirigée par Yves Lacoste, s'inscrit dans l'école de pensée de ce dernier en prétendant user de la géopolitique comme méthode d'analyse des rivalités de pouvoir.

2 L'introduction est alléchante, l'auteur mettant en perspective historique la construction de l'Etat saoudien moderne et ses composantes géopolitiques. Le premier chapitre décrit la genèse de l'Etat, en détaillant ses bases "sectaires ", c'est-à-dire comment le wahhabisme et le pouvoir des Saoud vont se lier, et comment après plusieurs échecs cette association va triompher dans la péninsule. A notre sens, c'est le chapitre le plus intéressant de l'ouvrage, où l'on comprend les bases politiques, religieuses et géographiques du royaume arabe. L'auteur explique très bien comment les ruraux sédentaires, d'où sont originaires les Saoud - qui ne sont donc pas des bédouins, comme on le prétend trop souvent -, vont consolider leur pouvoir, articulé entre pragmatisme envers les puissances européennes et expansionnisme basé sur la ferveur religieuse.

Dans un second chapitre, l'auteur étudie l'Arabie saoudite de la seconde moitié du XX siècle. Après une introduction rappelant des éléments de géographie physique, l'auteur décrit les quatre grandes régions composant le pays: le Nedj, berceau théologicopolitique; le Hassa, poumon économique; le Hedjaz, coeur religieux du monde 
musulman et enfin l'Assir, la marche méridionale. Vient alors la présentation des plans d'urbanisation de l'Etat et de la tentative de sédentarisation des bédouins. Ensuite l'auteur s'interroge sur l'existence d'une identité nationale saoudienne. Certes, ce chapitre est très intéressant et instructif mais on ne peut s'empêcher de rester sur notre faim, surtout concernant les conflits sociaux entre les différentes composantes de la population. La fin du chapitre deux s'attarde longuement sur la question de la succession du roi Fahd et des jeux de pouvoir à la cour. Le chapitre trois est exclusivement consacré à la politique de l'Arabie saoudite des attentats, des années 1990 à aujourd'hui. On est alors dans un ouvrage de politique et non de géopolitique. Seules les relations avec les Etats-Unis sont ainsi mentionnées. C'est bien dommage.

4 Au final, un ouvrage inégal. Passionnant quand il explique la mise en place du pouvoir saoudien, même si parfois la profusion de détails nuit à la compréhension globale, il se perd dans des commentaires politiques qui n'ont plus rien à voir avec la géographie ou la géopolitique. On regrettera l'absence d'une simple carte de localisation des provinces, des villes : la géographie de l'Arabie Saoudite n'est pas familière au grand public! Pour le reste, suggérons à l'auteur d'enrichir son analyse de données économiques bien traitées et d'exposer les conflits sociaux à l'oeuvre dans ce pays encore méconnu. 